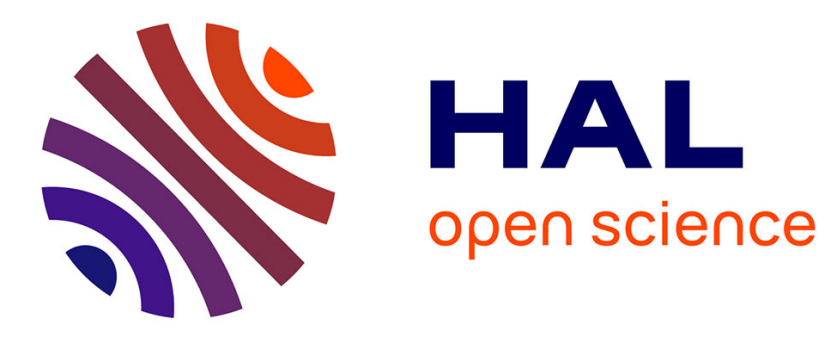

\title{
Mg based bulk metallic glasses with high mechanical strength and large forming capacity
}

Sylvain Puech, Jean-Jacques Blandin, Jean-Louis Soubeyroux

\section{To cite this version:}

Sylvain Puech, Jean-Jacques Blandin, Jean-Louis Soubeyroux. Mg based bulk metallic glasses with high mechanical strength and large forming capacity. Advanced Engineering Materials, 2007, 9 (9), pp.764-768. 10.1002/adem.200700160 . hal-00265084

\section{HAL Id: hal-00265084 \\ https://hal.science/hal-00265084}

Submitted on 18 Mar 2008

HAL is a multi-disciplinary open access archive for the deposit and dissemination of scientific research documents, whether they are published or not. The documents may come from teaching and research institutions in France or abroad, or from public or private research centers.
L'archive ouverte pluridisciplinaire HAL, est destinée au dépôt et à la diffusion de documents scientifiques de niveau recherche, publiés ou non, émanant des établissements d'enseignement et de recherche français ou étrangers, des laboratoires publics ou privés. 


\title{
Mg based bulk metallic glasses with high mechanical strength and
}

\section{large forming capacity}

\author{
S. Puech ${ }^{\mathrm{a}}$, J.J. Blandin ${ }^{\mathrm{a}}$, J.L. Soubeyroux ${ }^{\mathrm{b}}$ \\ ${ }^{a}$ Institut National Polytechnique de Grenoble (INPG), SIMAP laboratory, GPM2 Group, CNRS/UJF, BP 46, \\ 38402 Saint-Martin d'Hères, France \\ ${ }^{\mathrm{b}}$ CNRS Grenoble / CRETA, 25 avenue des Martyrs, BP166, 38042 Grenoble Cedex 9, France
}

\section{Introduction}

Grain size refinement is a well known technique to improve mechanical properties of metallic alloys. Fine grained materials can be produced by recrystallization after severe plastic deformation or thanks to rapid solidification techniques. At high enough cooling rates from liquid state, amorphous alloys can even be produced. In this case, the "liquid" structure is preserved down a critical temperature for which it is frozen. Up to 80 's, to avoid primary crystallization, very high cooling rates were required, leading to metallic glasses only under the form of ribbons. Today, thanks to appropriate compositions, bulk metallic glasses (BMG) can be produced. These materials exhibit attractive mechanical properties, in particular high strengths and large elastic domains at room temperature. Fig. 1 compares the tensile strengths and the Young's modulus of conventional metallic alloys with the corresponding bulk metallic glasses [1]. One can see that for all the studied alloys, the tensile strength is sharply increased for the amorphous structure whereas the Young's modulus is not significantly affected, leading to a particularly large elastic domain. 


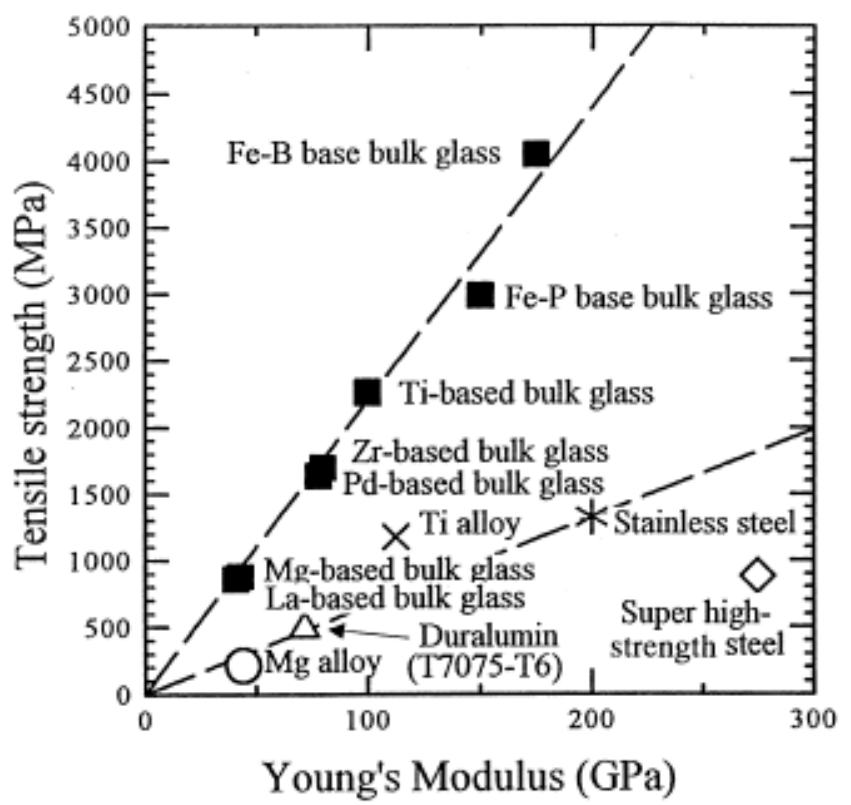

FIG. 1: Comparison of tensile strength and Young's modulus between conventional metallic alloys and the corresponding bulk metallic glasses [1].

In this context, $\mathrm{Mg}$ based BMGs appear of special interest since they can provide new light alloys for structural applications with net shape fabrication possibilities. A large number of studies have been carried out to find good glass former compositions for $\mathrm{Mg}$ alloys. Frequently, $\mathrm{Mg}-\mathrm{Cu}-\mathrm{RE}$ compositions have been selected. For instance, a $\mathrm{Mg}_{65} \mathrm{Cu}_{25} \mathrm{Y}_{10}$ glassy alloy was firstly reported by Inoue [2]. In the present work, various compositions close to the $\mathrm{Mg}_{65} \mathrm{Cu}_{25} \mathrm{Gd}_{10}$ one, initially suggested by Men [3], were investigated [4]. The resulting mechanical properties at room temperature were studied and a particular attention was also given to the forming capacity of theses alloys in their glass transition interval.

\section{Elaboration and characterization of Mg based BMGs}

Elements with purity better than $99.9 \%$ were used as starting materials. Copper and rareearths were first melted together in order to obtain a binary eutectic easier to melt with 
magnesium. The master alloy was re-melted several times to assure homogeneity. Amorphous rods of $6 \mathrm{~mm}$ diameter were obtained by copper mould casting in argon atmosphere, as illustrated by Fig. 2 [4].

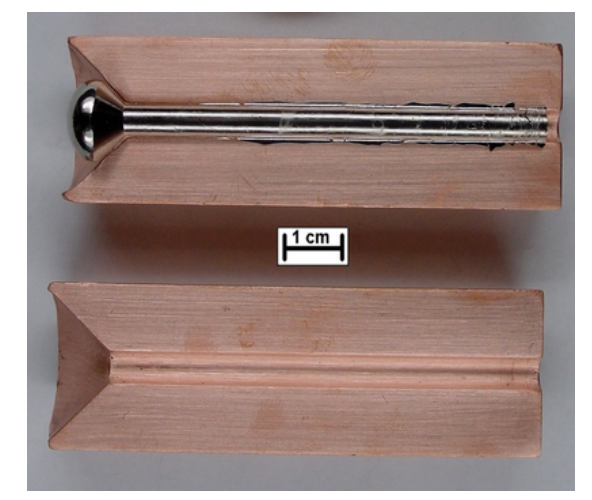

FIG. 2: Typical rods produced in the copper mould.

Fig. 3-a displays XRD patterns taken from the cross-section of the rods confirming the amorphous structure of the as-cast alloys (i.e. no diffraction peaks) whereas Fig. 3-b shows the corresponding DSC curves in continuous heating conditions (heating rate : $10 \mathrm{~K} / \mathrm{min}$.).

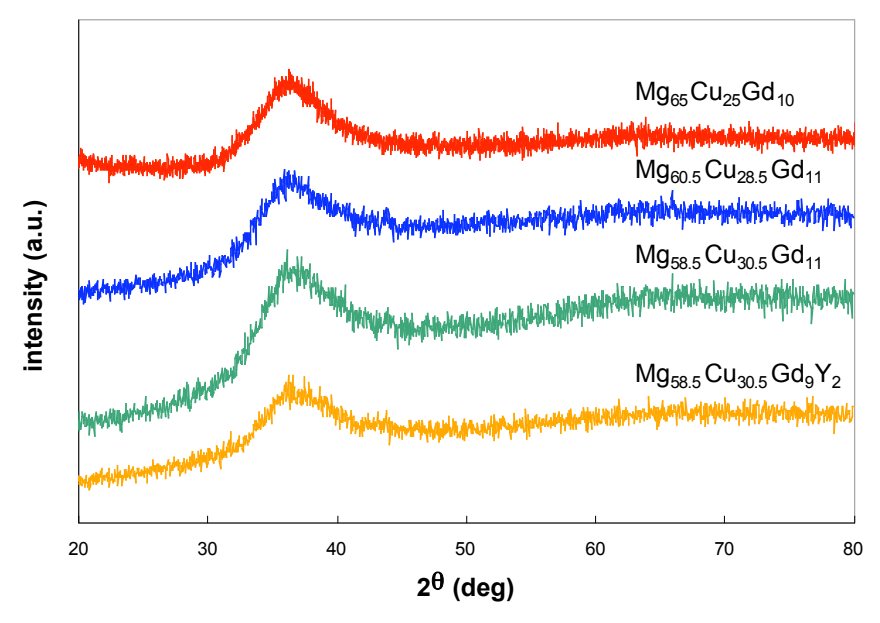

(a) 


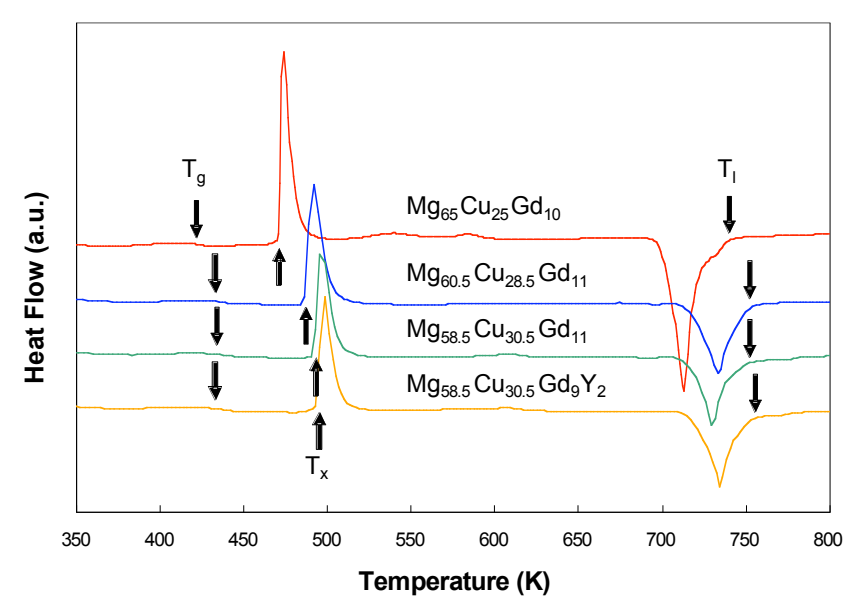

(b)

FIG. 3: (a) XRD and (b) DSC scans of the amorphous alloys

Whatever the investigated compositions, a glass transition temperature $\mathrm{T}_{\mathrm{g}}$ in the range $[415 \mathrm{~K}$ $-430 \mathrm{~K}]$ was measured, followed by a main crystallization peak with an onset crystallization temperature $T_{x}$ and melting event for higher temperatures $\left(T_{1}\right)$. Considering a further forming of the glass at high temperature, the interval $\Delta \mathrm{T}=\mathrm{T}_{\mathrm{x}}-\mathrm{T}_{\mathrm{g}}$ will be a first parameter to take into account. Moreover, from such data, several indicators have been proposed to evaluate the glass forming ability (GFA) for bulk metallic glasses. Among them, the $\gamma$ parameter $\left(=T_{x} /\left(T_{g}\right.\right.$ $\left.+T_{1}\right)$ ) is frequently used and it is generally considered that the maximum diameter $D_{c}$ for which an amorphous structure can be preserved, increases with $\gamma$. Experimentally, $D_{c}$ can be obtained after an elaboration in a cone-shaped mold followed by XRD characterizations of selected cross-sections [4]. Table 1 summaries the values of $T_{g}, T_{x}, T_{1}, \Delta T, \gamma$ and $D_{c}$ for the elaborated Mg BMGs and for other magnesium, zirconium, copper and palladium based BMGs [5]. 


\begin{tabular}{cccccccc}
\hline Composition (at.\%) & $\mathbf{T}_{\mathbf{g}}(\mathbf{K})$ & $\mathbf{T}_{\mathbf{x}}(\mathbf{K})$ & $\mathbf{T}_{\mathbf{l}}(\mathbf{K})$ & $\Delta \mathbf{T}$ & $\gamma$ & $\mathbf{D}_{\mathbf{c}}(\mathbf{m m})$ & Ref. \\
\hline $\mathrm{Mg}_{65} \mathrm{Cu}_{25} \mathrm{Gd}_{10}$ & 418 & 472 & 739 & 54 & 0.408 & 7 & This work \\
$\mathrm{Mg}_{60.5} \mathrm{Cu}_{28.5} \mathrm{Gd}_{11}$ & 425 & 485 & 755 & 60 & 0.411 & 8 & This work \\
$\mathrm{Mg}_{58.5} \mathrm{Cu}_{30.5} \mathrm{Gd}_{11}$ & 427 & 490 & 753 & 63 & 0.415 & 8 & This work \\
$\mathrm{Mg}_{58.5} \mathrm{Cu}_{30.5} \mathrm{Gd}_{9} \mathrm{Y}_{2}$ & 425 & 494 & 756 & 69 & 0.418 & 9 & This work \\
$\mathrm{Mg}_{65} \mathrm{Cu}_{25} \mathrm{Y}_{10}$ & 425 & 479 & 771 & 55 & 0.401 & 7 & {$[5]$} \\
$\mathrm{Mg}_{80} \mathrm{Ni}_{10} \mathrm{Nd}_{10}$ & 454 & 471 & 878 & 16 & 0.353 & 0.6 & {$[5]$} \\
$\mathrm{Zr}_{65} \mathrm{Al}_{7.5} \mathrm{Cu}_{17.5} \mathrm{Ni}_{10}$ & 657 & 736 & 1168 & 79 & 0.403 & 16 & {$[5]$} \\
$\mathrm{Pd}_{40} \mathrm{Cu}_{30} \mathrm{Ni}_{10} \mathrm{P}_{20}$ & 577 & 656 & 836 & 79 & 0.464 & 72 & {$[5]$} \\
$\mathrm{Cu}_{60} \mathrm{Zr}_{30} \mathrm{Ti}_{10}$ & 713 & 763 & 1151 & 50 & 0.409 & 4 & {$[5]$} \\
\hline
\end{tabular}

TABLE 1: Comparison of the thermal characteristics and critical diameters of the studied Mg amorphous alloys with those of other BMGs

In the case of the studied $\mathrm{Mg}$ based $\mathrm{BMG}$, values of $\Delta \mathrm{T}$ and $\gamma$ of about $60 \mathrm{~K}$ and 0.41 respectively are measured. These values are in good agreement with those frequently reported for other BMGs confirming that the GFA of appropriate magnesium alloys is of the same order than the GFA measured for other BMG compositions. Table I confirms also the necessity to optimize the composition since for instance in the case of $\mathrm{Mg}_{80} \mathrm{Ni}_{10} \mathrm{Nd}_{10}$, the value of $\gamma$ is significantly reduced leading to a very low $D_{c}$.

\section{Mechanical properties at room temperature}

At room temperature, BMG exhibit generally brittle behaviors in both compressive and tensile conditions. In the case of the $\mathrm{MgCuGd}(\mathrm{Y})$ glasses tested in compression, maximum stresses between 650 and $800 \mathrm{MPa}$ were measured with Young's modulus close to $45 \mathrm{GPa}$. Such fracture stresses are significantly larger than those generally obtained for conventional $\mathrm{Mg}$ alloys, even for high strength $\mathrm{Mg}$ alloys. For instance, in the case of Mg-Y-RE alloys (which are considered as high strength Mg alloys), yield strengths less than $300 \mathrm{MPa}$ are 
generally obtained in peak aged conditions [6]. Even in the particular case of ultra fine microstructures produced by severe plastic deformation techniques, strength levels of about $600 \mathrm{MPa}$ are not reached [7]. The Young's modulus of the Mg based BMG, measured by ultra sonic techniques, gives a value close to $45 \mathrm{GPa}$, confirming that the amorphous structure does not modify significantly this mechanical property. One can again underline that the combination of the values of the maximum strength and Young's modulus lead to a particularly large elastic domain since assuming a Hooke's law, a value of elastic strain of about 0.015 is estimated.

The mechanisms of deformation and fracture of BMGs are still under debate but typical features are often observed. The most frequently reported observation is related to the development of a vein pattern in the fracture zone, as it can be seen in the SEM observation shown in Fig. 4-a of the fractured $\mathrm{Mg}_{65} \mathrm{Cu}_{25} \mathrm{Gd}_{10}$ glass. This morphology suggests a rise of temperature in shear bands leading to a decrease in viscosity and a confined ductility of the glass [8]. However, in the case of magnesium based BMG, the sample does not fracture along a unique shear plane oriented roughly at $45^{\circ}$ in reference to the stress axis (as it can be observed for instance in the case of $\mathrm{Zr}$ based BMG [8]) but in a large number of pieces. Veins are mainly observed in the larger fractured parts whereas rivers are preferentially observed on the small parts, as illustrated by Fig. 4-b. Such rivers can be also observed in the case of $\mathrm{Zr}$ based BMG but only after partial crystallization of the glass for which brittleness is enhanced in comparison with the amorphous state [9]. 


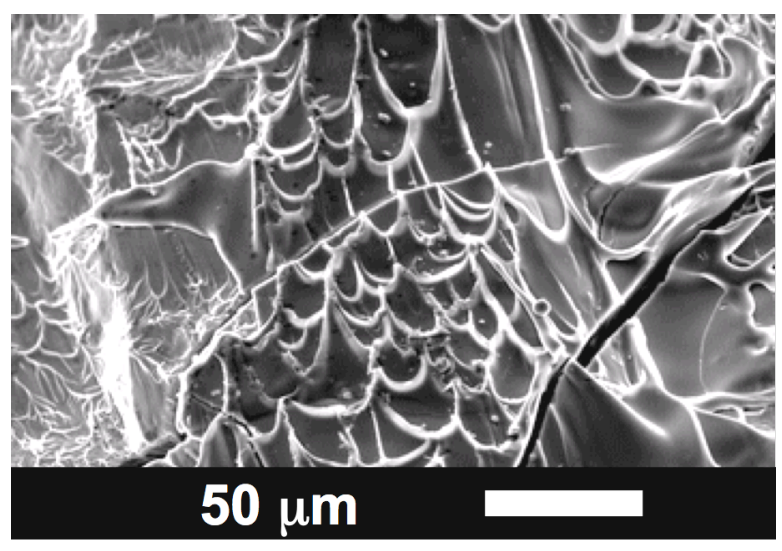

(a)

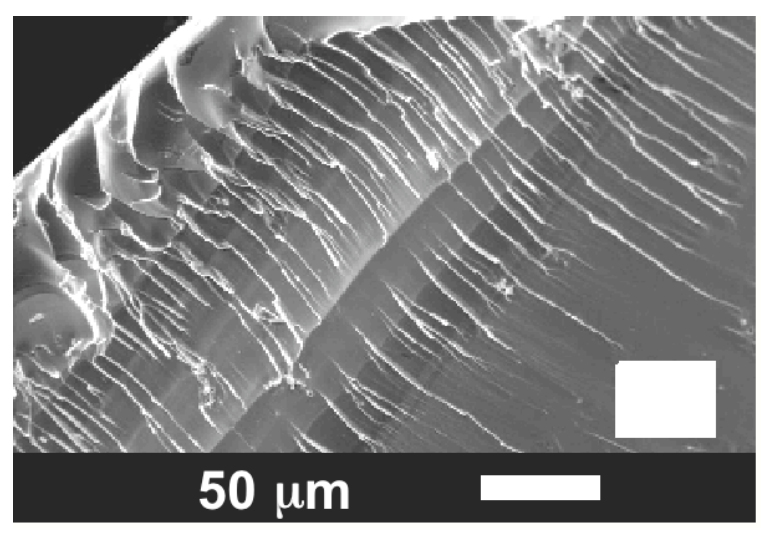

(b)

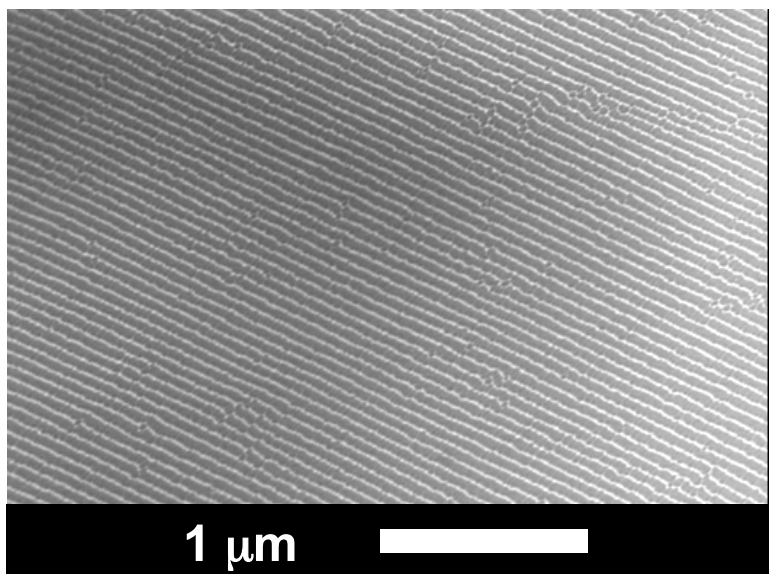

(c)

FIG. 4: Fracture surface of the amorphous alloy: (a) vein pattern, (b) rivers pattern, (c) enlarged observation

Fig. 4c displays an observation at higher magnification of the grey zone indicated in Fig. 4-b. At this scale, the observation reveals the existence of nanometer scale periodic wave with an average wavelength of about $60 \mathrm{~nm}$. Such corrugations have been very recently reported in the case of the fracture of a $\mathrm{Mg}_{65} \mathrm{Cu}_{25} \mathrm{~Tb}_{10}$ glass [10] and were attributed to interactions 
between the stress field of crack propagation and elastic waves produced by a release of fracture energy by acoustic emission. Even if additional work is needed before any conclusions concerning the correlation between the development of corrugations and the structure of the BMG, it seems that such observations are preferentially carried out for glasses displaying a relatively low fracture energy.

\section{Forming capacity at temperatures near $T_{g}$}

Due to their brittleness, $\mathrm{Mg}$ based BMG cannot be formed at room temperature. Casting of BMG is one way to get components but is not always straightforward since it requires to optimize cooling rates and castability, keeping in mind that these alloys exhibit particularly large viscosities in the liquid state. In consequence, forming in solid state can appear as a particularly interesting way. Moreover, as it can be obtained in the case of oxide glasses or polymers, BMGs exhibit a very large capacity of forming at temperatures higher than the glass transition temperature. This great forming ability results from a large plastic stability associated to the Newtonian rheology (i.e. viscosity independent upon strain rate) which can be quite easily obtained in this temperature domain.

Fig. 5 shows the variation with temperature and strain rate of the viscosity of the $\mathrm{Mg}_{65} \mathrm{Cu}_{25} \mathrm{Gd}_{10}$ glass. Compression tests were performed on cylinders of $4 \mathrm{~mm}$ diameter and 6 $\mathrm{mm}$ length and before tests, an holding time of $300 \mathrm{~s}$ was applied to ensure temperature stabilization. Strain rate typically between $10^{-4}$ and $10^{-2} \mathrm{~s}^{-1}$ were carried out for temperatures in the interval $\left[\mathrm{T}_{\mathrm{g}}-10 \mathrm{~K}, \mathrm{~T}_{\mathrm{g}}+20 \mathrm{~K}\right]$. Newtonian rheologies are obtained in a large part of the investigated domain and a transition from Newtonian to non-Newtonian (i.e. viscosity decreasing with increasing strain rate) behavior is observed only for low temperatures and/or 
high strain rates. Four conclusions can be drawn from this figure: $i$. the extrapolated Newtonian viscosity at $T_{\mathrm{g}}$ is close to $5.10^{10} \mathrm{~Pa} . \mathrm{s}$, which is significantly lower than the value of $10^{12}$ Pa.s frequently reported at $\mathrm{T}_{\mathrm{g}}$ for other BMGs $[11]$; ii. in the Newtonian domain, the viscosities depend strongly on temperature since viscosity is decreased by approximately a factor $10^{3}$ between $408 \mathrm{~K}$ and $438 \mathrm{~K}$; iii. At $438 \mathrm{~K}$, viscosities less than $10^{9}$ Pa.s are measured which means that forming can be carried out under very low stresses if moderate strain rates are compatible with the preservation of the amorphous structure during the forming process ; $i v . \mathrm{Mg}$ based BMG are not adapted for high temperature conditions of use.

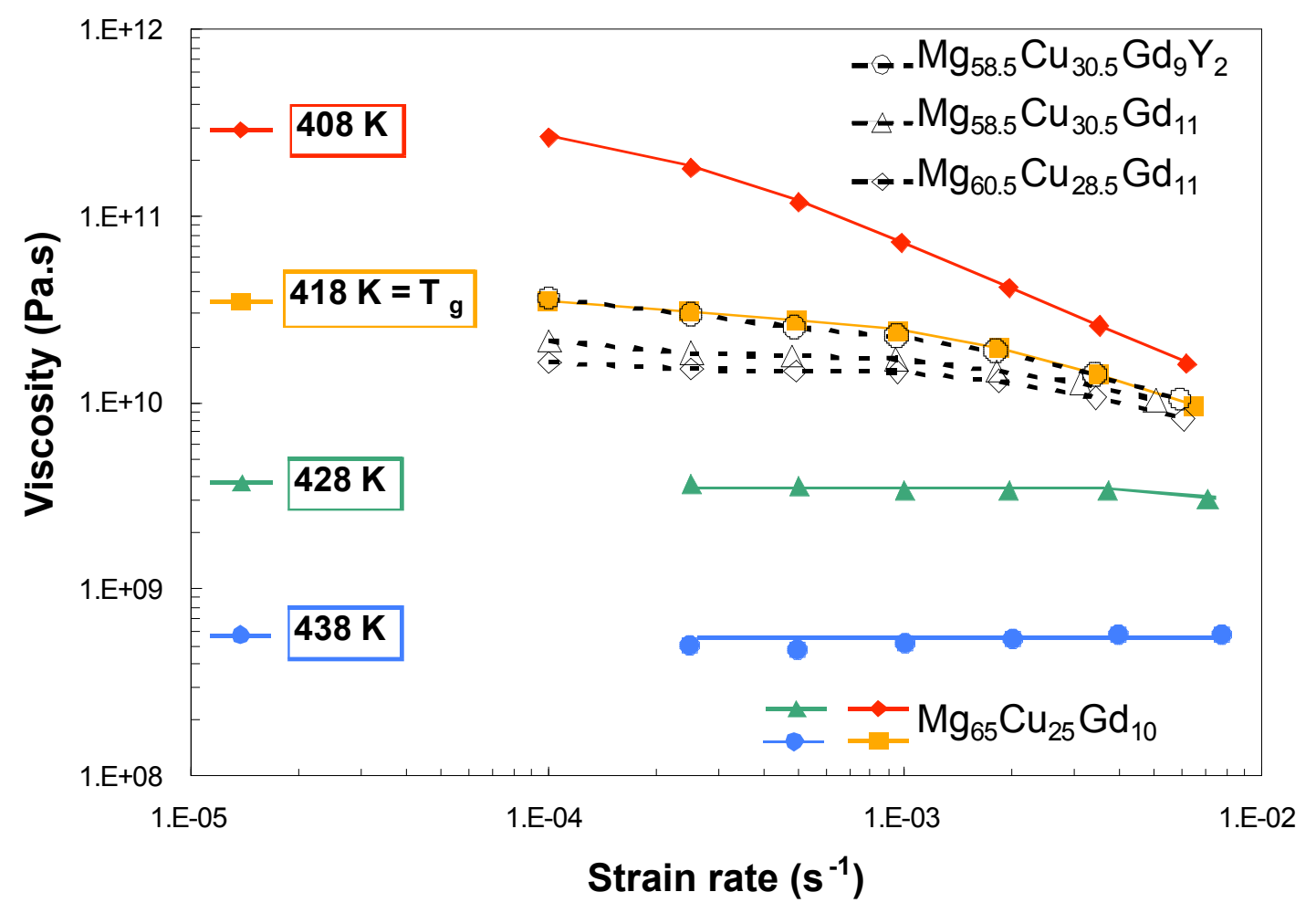

FIG. 5: Variation with temperature and strain rate of the viscosity of the studied glasses

Fig. 5 compares also the behaviors of all the investigated Mg BMGs deformed at their glass transition temperature. One can see that despite significant differences in compositions and in $\mathrm{Tg}$, the viscosities appear quite similar. These results suggest that the pertinent parameter to 
predict the viscosities of the glasses is $\mathrm{T} / \mathrm{Tg}$ rather than $\mathrm{T}$. Additional data are nevertheless required to confirm this conclusion.

The choice of the best experimental forming conditions in the case of BMGs is not straightforward since glasses are fundamentally out of equilibrium materials. In particular, at $\mathrm{T}>\mathrm{T}_{\mathrm{g}}$, crystallization can occur after a given incubation time. If such crystallization occurs during the forming process, it can modify strongly the viscosity. An example of this situation for the studied $\mathrm{Mg}_{65} \mathrm{Cu}_{25} \mathrm{Gd}_{10}$ is shown in Fig. 6. A constant strain rate $\left(5 \times 10^{-4} \mathrm{~s}^{-1}\right)$ compression test is performed at $\mathrm{T}_{\mathrm{g}}+20 \mathrm{~K}$ : the viscosity remains constant up to a strain of about 0.8 (corresponding to a total holding time of $30 \mathrm{~min}$.) and then increases strongly. One can however note that the alloy remains deformable in the studied experimental domain. Such an increase of viscosity can be correlated to crystallization and has already been reported for others BMGs [11]. In some cases, when crystallization becomes too high, the glass can no longer be deformed even at high temperature and the sample breaks down. In consequence, it is very important for each glass not only to get information about its thermal stability. For the studied $\mathrm{Mg}_{65} \mathrm{Cu}_{25} \mathrm{Gd}_{10}$ glass, isothermal DSC analysis performed at $\mathrm{T}_{\mathrm{g}}+20 \mathrm{~K}$ reveals that crystallization started after a 20 minutes incubation time and ended after roughly 50 minutes. These data were confirmed by TEM observations carried out after partial crystallization treatments. For instance, Fig. 7 displays a TEM observation of the alloy after a treatment of 40 min. at $438 \mathrm{~K}$. Two kinds of crystallites can be observed: rod shaped crystallites with characteristic size of 50 by $100 \mathrm{~nm}$ and spherical crystallites of roughly $200 \mathrm{~nm}$ in diameter. These two populations of crystallites were identified by $\mathrm{XRD}$ respectively as $\mathrm{Cu}_{2} \mathrm{Gd}$ and $\mathrm{Mg}_{2} \mathrm{Cu}$ phases. 


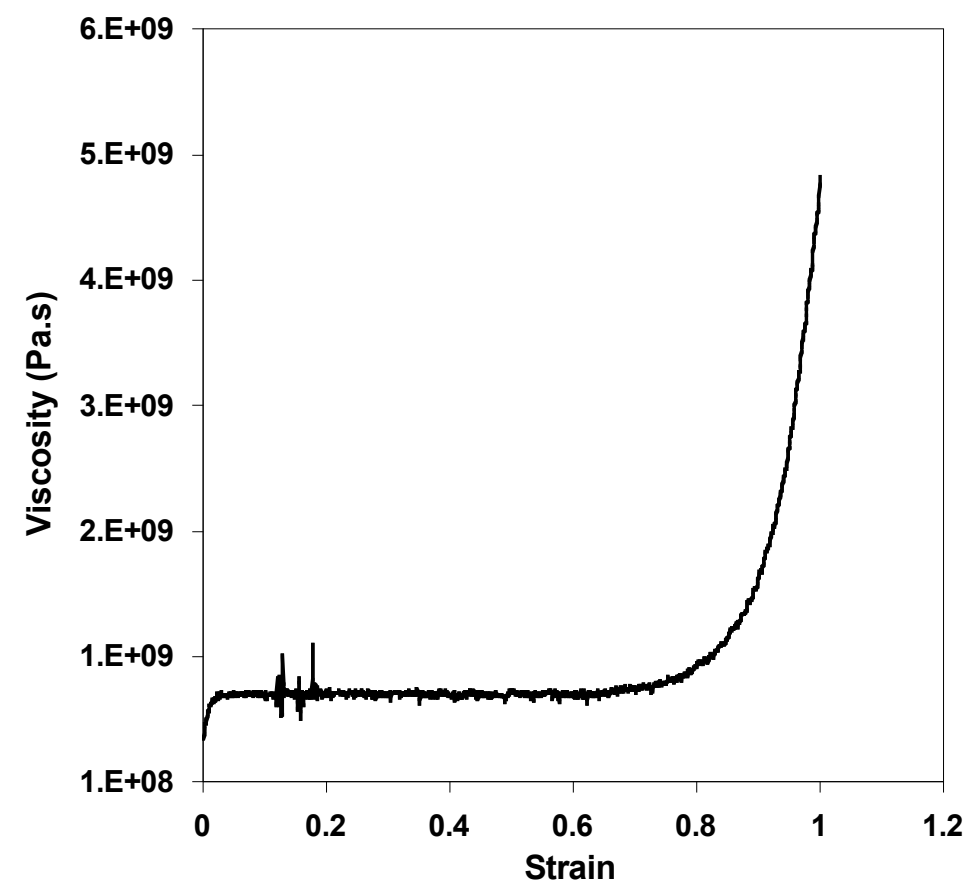

FIG. 6: Strain stress curve at $438 \mathrm{~K}$ for a $5 \times 10^{-4} \mathrm{~s}^{-1}$

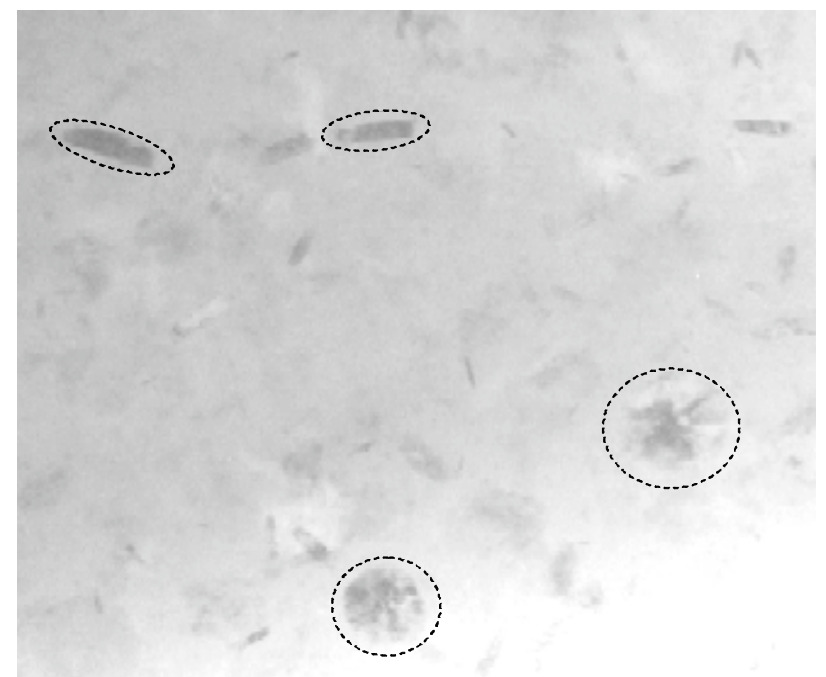

$300 K \mathrm{~V} \longmapsto 200 \mathrm{~nm}$

FIG. 7: TEM Bright field image of a 40 minute transformed sample

The effect on properties in use of such partial crystallization was also investigated since in some cases, the presence of nanocrystals can still increase the fracture stress [9]. However, for 
the studied $\mathrm{Mg}_{65} \mathrm{Cu}_{25} \mathrm{Gd}_{10}$ glass, even for limited quantities of crystals, the fracture stress continuously decreases and the initial value of fracture stress equal to $650 \mathrm{MPa}$ for the amorphous alloy was reduced to about $300 \mathrm{MPa}$ after complete transformation.

\section{Conclusion and perspectives}

Various Mg based BMG were successfully elaborated by copper mould casting. High strengths $(>600 \mathrm{MPa})$ were obtained in compression at room temperature associated with a large elastic strain $(\approx 0.015)$ but also to a macroscopically brittle behavior. Forming capacity in the glass transition interval has been investigated. For such temperatures, thanks to Newtonian rheologies, glasses exhibit a particularly good forming ability with low viscosities. However, in some cases, crystallization can occur during forming and increase sharply the viscosity.

Work is under progress to reduce the brittleness of such bulk metallic glasses at room temperature. In the case of $\mathrm{Zr}$ based $\mathrm{BMG}$, some results have been obtained by addition of appropriate elements, which in some cases, lead to a composite containing both ductile crystalline and brittle amorphous phases [12]. In the case of $\mathrm{Mg}$ based $\mathrm{BMG}$, some attempts were carried out adding iron to the nominal composition. In this case, macroscopic plasticity could be obtained at room temperature, maintaining high strength levels [13].

\section{Acknowledgements}

The authors thank Dr. P. Donnadieu from INPG / SIMAP laboratory, PM group for her help in the TEM observations. 


\section{References}

[1] A. Inoue, Acta Mater. 2000, 48, 279.

[2] A. Inoue, A. Kato, T. Zhang, S. G. Kim and T. Masumoto, Mater.Trans. JIM 1991, 32, 609.

[3] H. Men and D.H. Kim, J. Mater. Res. 2003, 18, 1502.

[4] J.L. Soubeyroux, S. Puech, J.J. Blandin, Mater. Sc. Eng. A in press.

[5] Z.P. Lu, C.T. Liu, Acta Mater. 2002, 50, 3501.

[6] M. Mabuchi, Y. Chino and H. Iwasaki, Mater. Trans. 2002, 43, 2063.

[7] J.J. Blandin, Mater. Sc. Forum 2003, 426-432, 551.

[8] Z.F. Zhang, G. He, J. Eckert and L. Schultz, Phys. Rev. Lett. 2003, 91, 45505.

[9] L.Q. Xing, C. Bertrand, J.-P. Dallas and M. Cornet, Mater. Sc. Eng. A 1998, 241, 216.

[10] X.K. Xi, D.Q. Zhao, M.X. Pan, W.H. Wang, Y.Wu and J.J. Lewandowski, Appl. Phys. Lett. 2006, 89, 181911.

[11] M. Blétry, P. Guyot, Y. Brechet, J.J. Blandin and J.L. Soubeyroux, Mater. Sc. Eng. A 2004, 387-389, 1005.

[12] C.C. Hays, C.P. Kim and W.L. Johnson, Mater. Sc. Eng. A 2001, 304-306, 650.

[13] H. Ma, J. Xu and E. Ma, Appl. Phys. Lett. 2003, 83, 2793. 